\title{
Choques macroeconómicos y reformas de las políticas: lecciones extraídas de la desaceleración económica de 1999 en Chile
}

\author{
Julio J. Guzmán
}

\section{Resumen}

Este artículo analiza la respuesta del Gobierno chileno a la recesión de 1999 tras la crisis financiera asiática, centrándose en las reformas de política macroeconómica y los factores institucionales que influyeron en dicha respuesta. El análisis se basa en un examen de la investigación anterior sobre el tema, que indica que determinadas políticas fiscales y monetarias adoptadas en 1997 y 1998 aumentaron los efectos de lo que inicialmente habían sido impactos externos. La disciplina fiscal y las sólidas instituciones públicas establecidas antes y después de tal recesión reforzaron las políticas chilenas de protección social. La reducción de la deuda pública en la década de 1990, junto con el Fondo de Estabilización de los Ingresos del Cobre establecido en 1985, la regla fiscal del superávit estructural introducida en 2000 y la nueva combinación de políticas fiscal, cambiaria y monetaria en dicha década redujeron la vulnerabilidad de Chile a las nuevas perturbaciones.

\section{Palabras clave}

Condiciones económicas, recesión económica, macroeconomía, política económica, gastos públicos, política fiscal, indicadores económicos, Chile

\section{Clasificación JEL}

H53, J21, J48

Autor

Julio J. Guzmán es profesor asistente en la Escuela de Gobierno de la Universidad Adolfo Ibáñez de Santiago, Chile. Correo electrónico: julio.guzman.c@uai.cl. 


\section{Introducción ${ }^{1}$}

Chile ha sido destacado como ejemplo de transición eficaz al crecimiento sostenido en América Latina (Ffrench-Davis y Machinea, 2007). Este logro ha sido consecuencia de las reformas económicas y las políticas macroeconómicas que han controlado la inflación y moderado los distintos ciclos económicos (OCDE, 2015). Los puntos fuertes de la economía chilena son su disciplina fiscal, una inflación baja, una apertura comercial considerable, un sistema financiero sólido, una alta calidad institucional y una buena infraestructura (De Gregorio, 2005)².

Estos valores económicos son el resultado de un proceso de aprendizaje que ha incluido éxitos y fracasos en la implementación de las políticas gubernamentales. Por ejemplo, la crisis de 1982-1983, derivada de desequilibrios macroeconómicos, generó consenso entre los actores políticos sobre la importancia de mantener la sostenibilidad fiscal durante los gobiernos democráticos de la década de 1990 (Arellano, 2005).

En este contexto, el presente artículo evalúa la experiencia chilena al hacer frente a la recesión de 1999 desencadenada por la crisis financiera asiática, prestando especial atención a las políticas macroeconómicas adoptadas y a los factores institucionales que influyeron en las medidas adoptadas por el Gobierno en respuesta a dicha recesión ${ }^{3}$. Este análisis tiene como propósito poner de relieve los puntos fuertes y débiles del proceso de aprendizaje por el que atravesó Chile a finales de la década de 1990 y principios de los años 2000, que influyó en las políticas macroeconómicas que aún se siguen practicando. De esta manera, es posible aportar ideas para las reformas normativas de otros países y difundir lecciones transfronterizas sobre las respuestas gubernamentales durante las recesiones. El análisis se basa en un examen de los trabajos de investigación anteriores sobre este tema, haciendo especial hincapié en los estudios chilenos existentes.

En 1998 Chile afrontó un cambio profundo en las condiciones externas. La crisis asiática alcanzó proporciones mundiales y redujo los flujos de capital a Chile en un tercio de lo que habían sido en el período 1990 a 1997. Asimismo, los términos de intercambio del país decrecieron en un 12,5\% en 1998, con el consiguiente resultado de un déficit por cuenta corriente que llegó hasta el 6,5\% del producto interno bruto (PIB) en el tercer trimestre de ese año.

Nuestro examen de los trabajos de investigación anteriores sugiere que la política de ajuste adoptada por las autoridades chilenas durante 1998 incrementó los efectos de esos choques externos iniciales. Hubo falta de coordinación entre la política fiscal y la monetaria, y el ajuste monetario coincidió con una política fiscal expansiva. Así, la carga de la política de ajuste recayó casi exclusivamente en la política monetaria (Corbo y Tessada, 2003). Además, hubo inquietudes exageradas de que una alta transmisión de la depreciación a la inflación pondría en peligro el logro de la meta de inflación del año siguiente. Ello dio lugar a un ajuste monetario desproporcionado y por consiguiente a un episodio de iliquidez que produjo una contracción de la economía en 1998 mayor a lo que era necesario para ajustar el gasto interno. Una cierta inflexibilidad del mercado laboral junto con un plan trienal de aumentos en el salario mínimo intensificaron los efectos de desempleo de las perturbaciones iniciales

\footnotetext{
1 El autor agradece a un árbitro anónimo por sus valiosos comentarios. También expresa su reconocimiento a Emanuele Baldacci, Polly Jones, Andrew Mason y Truman Packard por sus útiles observaciones sobre una versión anterior de este estudio y a Maris Goldman, Thomas Marhoefer, Divya Mathur, Kathryn McLellan, Claudio Montenegro y Heidi Smith por su ayuda. Cualquier limitación y error presentes en este artículo corresponden por entero a la opinión del autor.

2 Sin embargo, el modelo chileno de desarrollo ha suscitado algunas preocupaciones sobre su capacidad para generar crecimiento inclusivo y apoyo a los grupos en situación de alta vulnerabilidad (véase, por ejemplo, Contreras, 2009; Mayol, 2012; Atria y otros, 2013; Atria, 2014).

3 Este estudio analiza la desaceleración económica de 1999 ocasionada por la crisis financiera asiática en vez de la más reciente crisis financiera de 2008 (la Gran Recesión) porque ello permite examinar la sostenibilidad a largo plazo de las reformas chilenas adoptadas tiempo después, mientras que las consecuencias de la crisis de 2008 y las subsiguientes recesiones europeas aún persisten.
} 
y de las políticas macroeconómicas adoptadas, a raíz de lo cual en 1999 se registró un crecimiento negativo del PIB del $-0,8 \%$, el primer año con un crecimiento negativo desde la crisis de deuda acaecida en América Latina en 1982 y 1983, así como un aumento de la tasa de desempleo, que pasó del 6,1\% en 1997 al 9,7\% en 1999.

Aunque la política de ajuste adoptada durante la recesión de 1999 puede juzgarse como inapropiada si hablamos en retrospectiva, la disciplina fiscal y las sólidas instituciones públicas establecidas antes, y especialmente después de la recesión, reforzaron las políticas chilenas de protección social. En particular, en el presente estudio se señalan cinco factores clave que incidieron positivamente en la capacidad de Chile para hacer frente a los efectos de la crisis de 1999: i) la reducción de la deuda pública durante la década de 1990; ii) el Fondo de Estabilización de los Ingresos del Cobre (FEC) creado en 1985; iii) la regla fiscal del superávit estructural de 2000; iv) la nueva combinación de políticas fiscal y monetaria del siglo XXl; y v) las medidas preparatorias adoptadas por el Banco Central antes de implementar el sistema cambiario de libre flotación. Este nuevo marco normativo permitió que se aplicara una política fiscal contracíclica en el período 2000-2003 y durante la última crisis financiera (la Gran Recesión).

En el presente artículo se examinan tres factores clave que afectaron la capacidad del país de aumentar los programas de protección social durante la crisis: i) una falta de interacción sistemática entre los programas y la duplicación de funciones y objetivos; ii) una capacidad administrativa inadecuada antes de la crisis para gestionar los programas de empleo; y iii) una inercia en los gastos fiscales incurridos antes de la crisis.

El resto del artículo se organiza del modo siguiente: en la sección II se resume la naturaleza y las consecuencias macroeconómicas de la crisis de 1999; en la sección III se presenta una evaluación de las medidas de respuesta adoptadas por el Gobierno durante la recesión, incluidas las políticas macroeconómicas, el gasto fiscal y los programas de empleo; la sección IV describe los factores institucionales que afectaron a la capacidad del país de incrementar los programas de protección social durante la recesión; y en la sección $\vee$ se extraen las correspondientes conclusiones.

\section{La desaceleración económica de 1999: causas y consecuencias}

En 1998 las condiciones externas a las que hacía frente Chile cambiaron profundamente en relación con las de años anteriores. La crisis asiática afectó en un principio a las economías asiáticas emergentes, pero más tarde alcanzó proporciones mundiales, extendiéndose a Rusia y a los países de América Latina. Esta crisis financiera internacional redujo abruptamente las entradas de capital a Chile, que pasaron de una media del 6,8\% del PIB en el período de 1990 a 1997 al 2,5\% del PIB en 1998 (véase el cuadro 1).

Simultáneamente, los mercados internacionales de las principales exportaciones de Chile se estaban viendo afectados por un menor crecimiento de las economías asiáticas. En 1998, los términos de intercambio de Chile disminuyeron en un 12,5\%. En líneas generales, la economía chilena hizo frente a condiciones externas especialmente duras tras el advenimiento de la crisis asiática, perdiendo recursos equivalentes al 6,2\% del PIB en 1999 como consecuencia del efecto combinado de la caída en los términos de intercambio, el descenso en los volúmenes de exportaciones y la reducción de las entradas de capital (véase el índice de condiciones externas en el cuadro 1). 


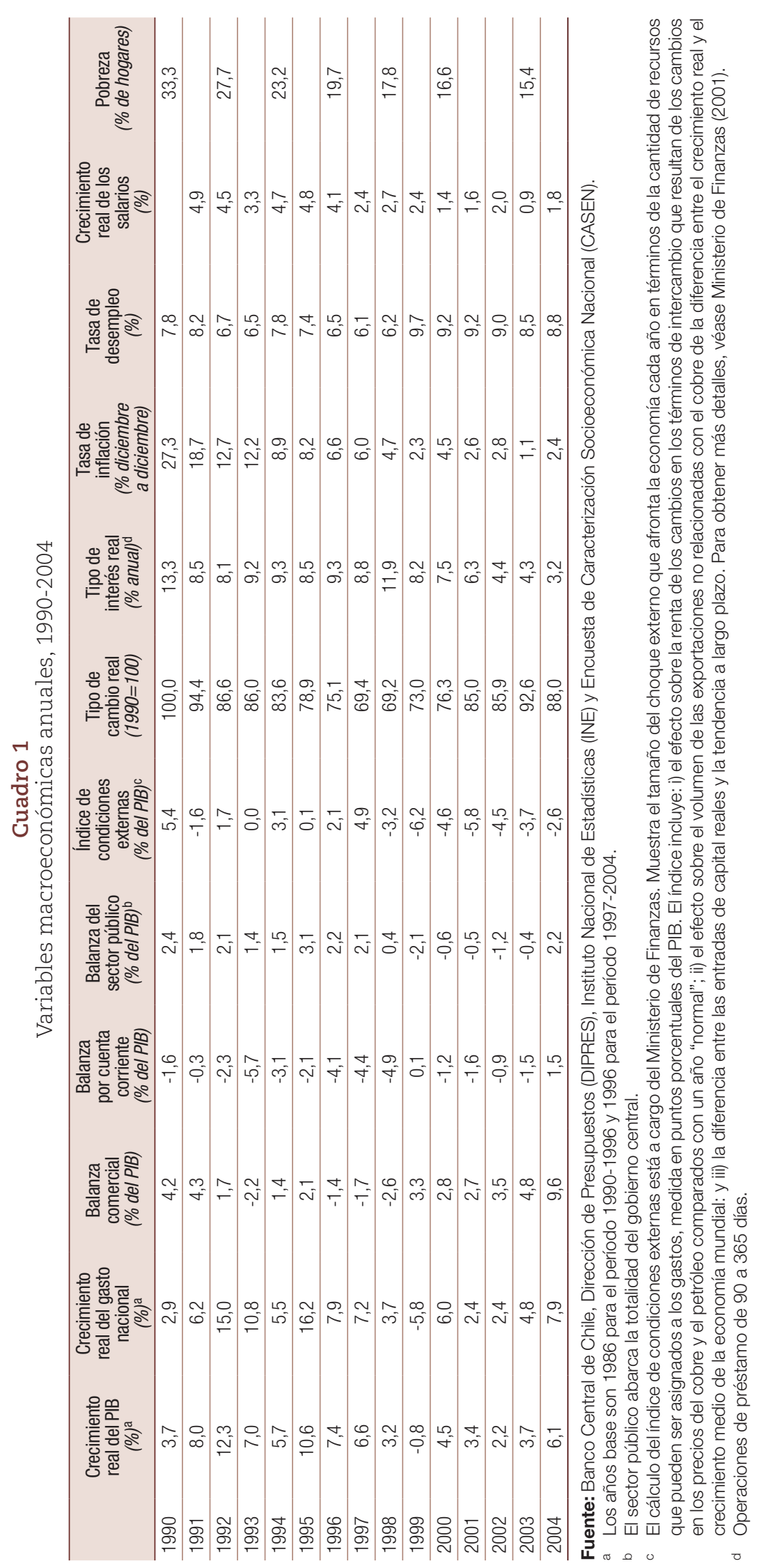


Estas condiciones externas negativas coincidieron con un recalentamiento de la economía nacional debido a una gran expansión del gasto interno en 1997. En el primer trimestre de 1998, por ejemplo, el crecimiento del gasto interno fue casi el doble del crecimiento del PIB (12,8\% frente a un 6,8\%). Por consiguiente, el déficit por cuenta corriente alcanzó un máximo del 6,5\% del PIB en el tercer trimestre de $1998^{4}$.

Además, la moneda fue objeto de varios ataques especulativos a causa del contagio de las crisis externas que estaban viviendo los mercados latinoamericanos. El Banco Central optó por defender el tipo de cambio para prevenir la depreciación. No obstante, el ajuste monetario fue acompañado de una política fiscal expansiva, de tal forma que la política fiscal y monetaria operó con objetivos contradictorios (Corbo y Tessada, 2003). Por ende, el ajuste se consiguió mayormente gracias a una política monetaria más restrictiva, lo que dio lugar a un ajuste monetario excesivo que su vez generó un episodio de iliquidez a finales de 1998.

Los choques externos y el episodio de iliquidez en 1998 propiciaron una contracción de la economía más allá de lo que era necesario para ajustar los gastos nacionales. Hubo una reacción excesiva en el PIB y en la tasa de empleo. Después de alcanzar su nivel máximo a principios de 1998, el PIB y el gasto interno (el consumo privado y público más la inversión total) empezaron a decrecer rápidamente después de adoptarse las políticas de ajuste. La tasa de crecimiento anual del PIB se redujo en más de 10 puntos porcentuales en solo 12 meses, pasando del 8,2\% en el cuarto trimestre de 1997 al -2,3\% en el cuarto trimestre de 1998. A finales del tercer trimestre de 1998, los elevados tipos de interés de los meses anteriores habían contribuido a una fuerte contracción del gasto interno, que hizo bajar en gran medida el déficit por cuenta corriente.

La actividad económica tocó fondo en el segundo trimestre de 1999, llegando a registrarse una reducción del PIB del 4,1\% y una contracción interanual del 10,1\% del gasto interno. De este modo, la economía tuvo cuatro trimestres consecutivos de crecimiento negativo del PIB (del cuarto trimestre de 1998 al tercer trimestre de 1999) que finalizaron en 1999 con una tasa de -0,8\%. Este fue el primer año de crecimiento negativo desde la crisis de deuda latinoamericana de 1982 y 1983. Los declives más pronunciados se dieron en el consumo privado y la inversión fija (Corbo y Tessada, 2003). El crecimiento de la inversión fue negativo durante cinco trimestres (del cuarto trimestre de 1998 al cuarto trimestre de 1999) y la tasa del cuarto trimestre llegó a caer en un 25,6\% en el segundo trimestre de 1999.

El desempleo empezó a elevarse a finales de 1998, alcanzando un máximo del 11,3\% en el tercer trimestre de 1999. A partir de ese momento comenzó a disminuir ligeramente, pero registró grandes fluctuaciones estacionales. La tasa media de desempleo aumentó del 6,8\% durante el período 1994-1998 al 9,7\% en 1999. Seis años después del inicio de la crisis, en 2004, el desempleo todavía era superior a la media del período 1990-1997 a pesar del repunte del crecimiento registrado desde finales de 2003. Es probable que las nuevas condiciones externas adversas a las que se enfrentó Chile en 2001 y 2002 (véase el cuadro 1) también afectaran a la recuperación del empleo5.

El cuadro 1 también muestra la evolución del índice de salario real. Puede observarse que el crecimiento del salario real alcanzó un promedio del 1,8\% anual en el período 1999-2001, un 1,9\% menos que la media de los cinco años anteriores (3,7\% durante el período 1994-1998). Por otro lado, continuó la tendencia decreciente en la inflación desde 1990 y los precios aumentaron un 2,3\% en 1999 en comparación con el 4,7\% del año anterior. La fuerte defensa del tipo de cambio nominal

\footnotetext{
4 Aunque la política monetaria se centró en cumplir la meta de inflación, también consistía en controlar el tamaño del déficit por cuenta corriente. A diferencia de otros bancos centrales independientes, el Banco Central de Chile es también responsable del sistema y la política cambiarios.

5 Las condiciones externas de la economía chilena se deterioraron en 2001-2002 debido a una bajada abrupta en la actividad económica de los países desarrollados y un declive del comercio mundial, agravados ambos hechos por los atentados terroristas del 11 de septiembre de 2001.
} 
llevada a cabo por las autoridades monetarias y la reducción de la presión del gasto interno siguió afectando a la inflación, llevándola a un punto más bajo de lo deseado o esperado en 1999.

Las políticas nacionales más expansivas adoptadas en 1999, junto con una mejora gradual del ambiente externo, trajeron consigo una rápida recuperación de la actividad económica en la última parte del año.

En líneas generales, aunque los efectos económicos de la recesión de 1999 fueron moderados y transitorios, los impactos sociales como el desempleo duraron más tiempo. De hecho, el PIB per cápita solo necesitó un año para volver a su nivel anterior a la recesión (medido en términos reales y en moneda chilena), mientras que la tasa de desempleo se mantuvo constantemente por encima de su nivel previo a la recesión.

\section{Políticas adoptadas por el Gobierno}

\section{Políticas macroeconómicas adoptadas después de los impactos iniciales}

La combinación de fuertes perturbaciones externas y el rápido crecimiento del déficit por cuenta corriente registrado en 1998 forzaron a las autoridades chilenas a adoptar una política de ajuste para corregir la senda del gasto. Sin embargo, las políticas fiscal y monetaria aprobadas después de los impactos no estuvieron coordinadas y el período de ajuste coincidió con una política fiscal expansiva (Corbo y Tessada, 2003).

El presupuesto fiscal para 1998 se planificó asumiendo que el crecimiento del PIB aumentaría hasta el $7 \%$ pero al final fue del 3,2\%. Aunque las autoridades contrajeron el gasto fiscal tres veces más en 1998 (Dirección de Presupuestos, 1999), la carga del ajuste recayó casi exclusivamente en la política monetaria. Además, en 1998 las autoridades subieron los salarios del sector público en un $6 \%$ e introdujeron un plan trienal de aumentos anuales superiores al $10 \%$ del salario mínimo nominal. A consecuencia de estas medidas el cambio de políticas pasó a ser más difícil y costoso en términos de desempleo.

La política monetaria procuró llegar al equilibrio correcto entre la meta de inflación y la caída en la actividad real. Después de los ataques especulativos a la moneda, el Banco Central se encontró en una situación difícil; finalmente optó por defender el tipo de cambio y no permitir una depreciación de la moneda. Sin embargo, hubo preocupaciones excesivas de que una depreciación rápida del peso pondría en peligro el logro de la meta de inflación. El Banco Central empezó entonces a vender reservas extranjeras y, en enero de 1998, a subir su tipo de interés. A medida que empeoraba el ambiente externo y aumentaba la expectativa de depreciación, el tipo de interés del mercado se elevó muy por encima del tipo de interés fijado por el Banco Central, lo que afectó seriamente la liquidez financiera del mercado. En realidad, el tipo de interés anual a un día alcanzó sus valores más altos de la década, superándolo en 23 puntos porcentuales en septiembre de 1998 (véase el gráfico 1).

En junio y en agosto de 1998, el declive de la economía rusa y la creciente presión sobre la moneda brasileña provocaron dos nuevos ataques especulativos contra el peso. Después de estos ataques, el Banco Central adoptó medidas adicionales que incluyeron estrechar la banda cambiaria, reducir los requisitos de reserva para los flujos de capital y elevar su tipo de interés al 14\% en septiembre de 1998 para poder ejercer cierto control sobre el establecimiento del tipo de interés del mercado ${ }^{6}$.

\footnotetext{
6 Véase Corbo y Tessada (2003) para obtener más detalles de las medidas adoptadas.
} 


\section{Gráfico 1}

Tasa de interés del mercado y tasa de interés fijada por el Banco Central, 1997-2000

(Tasas interbancarias a un día anuales y porcentuales)

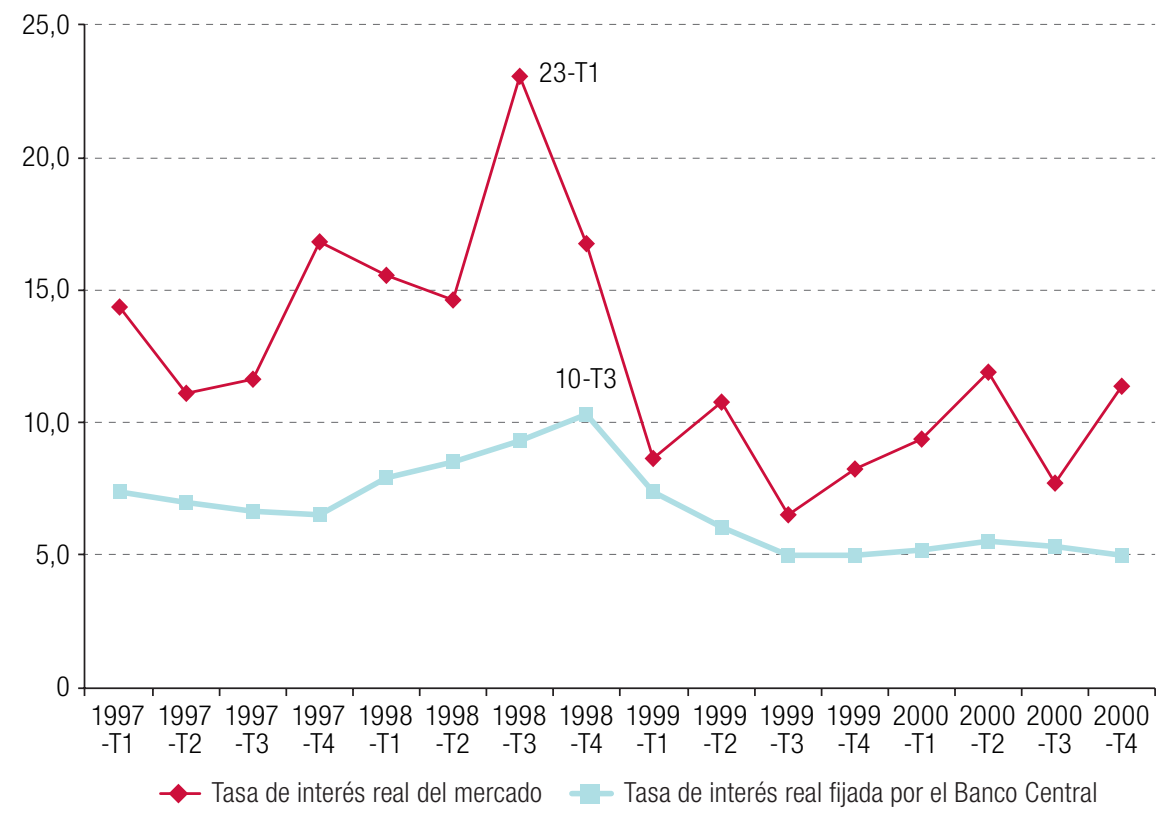

Fuente: Banco Central de Chile.

En 1999, cuando quedó claro que la reacción al gasto nacional había sido exagerada, las autoridades empezaron a reorientar la política fiscal y monetaria hacia un ciclo expansivo. En 1999 el Banco Central redujo su tipo de interés varias veces y el gasto fiscal aumentó en un 4,5\%, es decir un $5,3 \%$ más que el PIB registrado en el mismo período (-0,8\%).

Hay pruebas de que la política de ajuste llevada a cabo exacerbó los efectos de los choques externos de 1998 (Corbo y Tessada, 2003). El episodio de iliquidez de 1998 produjo una contracción de la economía más allá de lo que resultaba necesario para ajustar los gastos internos. Esto afectó en gran medida la inversión del sector privado y las decisiones de consumo y tuvo repercusiones prolongadas en el desempleo.

Teniendo en cuenta la expectativa de un nuevo incremento en el déficit por cuenta corriente, la respuesta adecuada habría sido aplicar una combinación de políticas fiscal y monetaria destinadas a moderar el gasto al tiempo que se facilitaba la depreciación real necesaria para el cambio. Dado que el tipo de cambio ya estaba en el extremo más alto de la banda meta, la combinación correcta habría sido adoptar una política fiscal restrictiva y una política monetaria de apoyo a la depreciación nominal y real de la moneda. Un presupuesto fiscal más restringido para 1998 y menores aumentos de los salarios habrían ayudado a ajustar el gasto interno sin depender exclusivamente de la política monetaria (Corbo y Tessada, 2003) ${ }^{7}$.

Las políticas cambiarias rígidas sin la opción de una política monetaria independiente pueden mejorar la credibilidad, pero también pueden hacer que el ajuste a los choques sea más penoso cuando los mercados laborales son inflexibles o la política fiscal es inadecuada (De Ferranti y otros, 2000). Esto se aplica a la respuesta de políticas inicial que dio Chile durante el turbulento período de 1997-1998.

7 De Gregorio y Tokman (2005) incluso afirman que en 1998 no había razones para permanecer en la banda cambiaria y argumentan que, dada la secuencia de los choques externos, un cambio más rápido hacia un régimen cambiario plenamente flexible habría suavizado los costos del ajuste que afrontó la economía chilena durante la crisis de 1999. Por otro lado, Morandé y Tapia (2002) insisten en que salir de la banda durante el ataque contra el peso en 1998 podría haber dado lugar a una reacción cambiaria desmesurada, lo que induciría a unos efectos negativos reales. 
La defensa del tipo de cambio contra los ataques especulativos de 1998 preservó la credibilidad de la política monetaria. Sin embargo, la incapacidad de las autoridades de alcanzar una combinación equilibrada de las políticas fiscal y monetaria, junto con cierto grado de inflexibilidad de los mercados laborales, dio lugar a un ajuste costoso de los choques en lo relativo al desempleo.

En la segunda mitad de 1999, Chile comenzó a adoptar una nueva combinación de políticas fiscal y monetaria. En septiembre de ese año, el Banco Central redefinió su meta de inflación, anunciando que el objetivo nuevo era mantener la inflación anual dentro de la gama del $2 \%$ al $4 \%{ }^{8}$. Al mismo tiempo, sustituyó al sistema de banda cambiaria por un interés variable destinado a dar al Banco Central más autonomía para llevar a cabo la política monetaria y hacer frente a los impactos externos, incluidos los cambios en los términos de intercambio externos y los tipos de interés. Por último, en 2000, el Gobierno introdujo una regla fiscal basada en un superávit estructural del 1\% del PIB a fin de reafirmar su compromiso con la responsabilidad fiscal ${ }^{9}$.

A diferencia de otros países que experimentaron graves perturbaciones en el cambio de un sistema cambiario fijo a otro variable (por ejemplo, el Brasil en 1999 y el Uruguay en 2002), la transición de Chile a un régimen de tipo de cambio flotante se realizó sin mayores contratiempos. No fue un cambio repentino en la forma en que se llevaba a cabo la política cambiaria. Al contrario, durante gran parte de la década de 1990 la banda cambiaria imitó a la flexibilidad cambiaria, y se modificaron los parámetros para validar las presiones del mercado (Morandé y Tapia, 2002). La banda deslizante se amplió con el tiempo en respuesta a los aumentos en las entradas de capital, las condiciones económicas cambiantes y las prioridades políticas hasta que fue finalmente abolida en 1999 (Duttagupta, Fernández y Karacadag, 2005; Ötker-Robe y otros, 2007).

Esta transición gradual evitó los efectos negativos reales que podrían haber sido causados por una reacción cambiaria excesiva ${ }^{10}$. Morandé y Tapia (2002) sostienen que la experiencia chilena posterior a la adopción de un tipo de cambio flexible fue relativamente tranquila. La inflación subyacente se mantuvo cercana a la meta estable, gracias a la escasa transmisión de las variaciones del tipo de cambio a la inflación nacional. En comparación con otros países, la volatilidad cambiaria aumentó solo marginalmente. Asimismo, la liberalización cambiaria no produjo ningún descalce de monedas importante en el sector privado que podría haber causado repercusiones en el balance general, así como graves dificultades financieras.

Estos resultados positivos se debieron a determinadas precondiciones favorables que estuvieron presentes antes del cambio de interés fijo a variable y a las medidas preparatorias adoptadas por el Banco Central antes del paso al régimen de tipo de cambio flotante. Entre las precondiciones favorables cabe mencionar varios elementos que ya estaban presentes antes de 1999: la independencia y responsabilidad del Banco Central, el mandato que tenía el Banco Central de fijarse como principal objetivo una meta explícita de inflación, una dolarización limitada del sistema bancario (en contraste con los principios de la década de 1980) y un sector financiero sólido y regulado. Las medidas preparatorias abarcaron, entre otras cosas, el fortalecimiento de las regulaciones contra los descalces de moneda, la liberalización de los mercados de derivados y la liberalización de las entradas de capital (para un análisis más detallado de las medidas preparatorias adoptadas, véase la sección IV.1 e)).

\footnotetext{
8 Anteriormente, al principio de 1994, el Banco Central había establecido cada año una estimación puntual para la inflación.

9 Para obtener más detalles de la nueva regla fiscal, véase la sección IV.

10 Calvo y Reinhart (2002) argumentan que las autoridades suelen tener "miedo al régimen de tipo de cambio flotante", es decir, son reacias a aplicar sistemas de total flotación debido a los posibles efectos negativos de la volatilidad cambiaria sobre el sistema financiero y los balances contables de las empresas.
} 


\section{Gasto fiscal y programas de empleo de emergencia}

La nueva combinación de políticas fiscal y monetaria implementada en 1999 hizo posible la ejecución de una política fiscal anticíclica en el período 2000-2002, durante el cual los tipos de interés se mantuvieron en niveles muy bajos. El gráfico 2 sirve para ilustrar este punto. Su eje principal presenta la evolución de 1996 a 2005 del gasto fiscal total, el gasto en protección social y el gasto en desempleo como porcentajes del PIB. Los gastos en protección social son la categoría principal del gasto fiscal. El gasto en desempleo es uno de los elementos que hay en esta categoría e incluye el gasto en programas de empleo de emergencia. Para dar una imagen de su evolución en el tiempo, los tres coeficientes se miden con relación a sus valores respectivos registrados en 1996 (1996=100).

\section{Gráfico 2}

Gasto fiscal por tipo y tasa de interés fijada por el Banco Central, 1996-2005

(En indices y porcentajes)

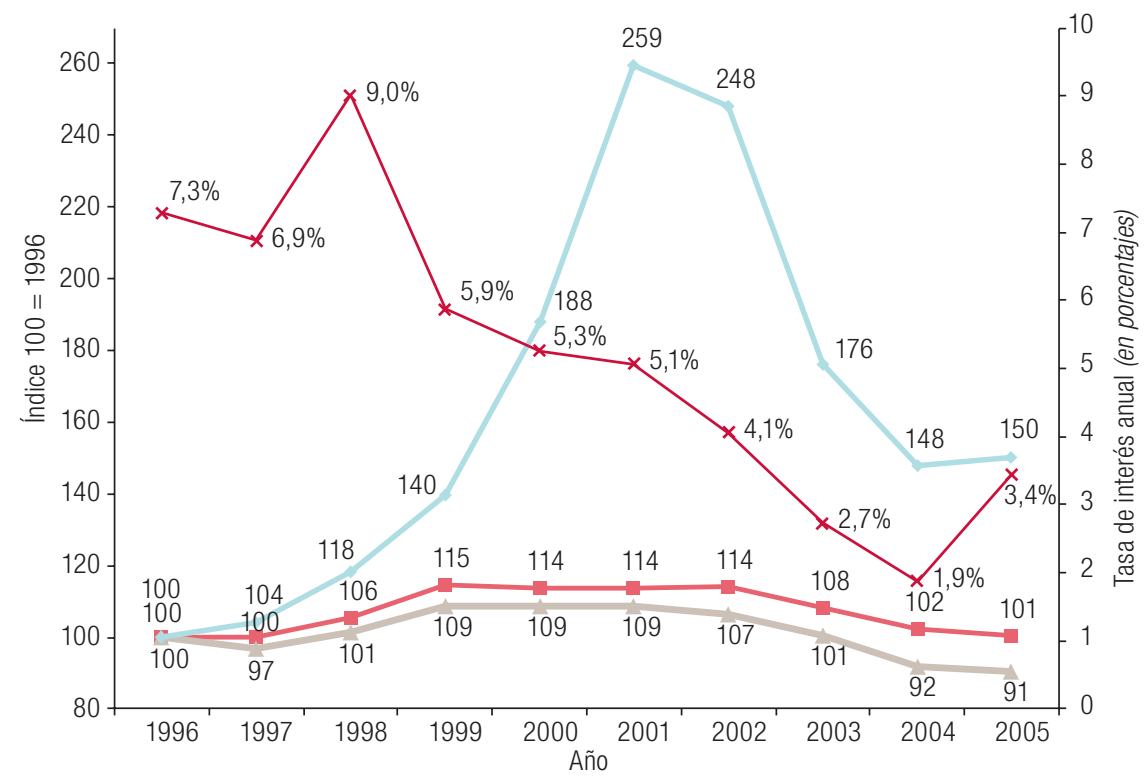

$*$ Tasa de interés real fijada por el Banco Central $\leadsto$ Gasto en desempleo $\neg$ Gasto fiscal total $\rightarrow$ Gasto en protección social

Fuente: Dirección de Presupuestos (DIPRES) y Banco Central de Chile.

En el gráfico se muestra que en 1998 y 1999 los gastos fiscales crecieron más que el PIB, pero el tipo de interés fijado por el Banco Central permaneció bastante alto durante dicho período. Por el contrario, en el período 2000 a 2002 los gastos fiscales aumentaron al mismo ritmo que el PIB, aunque el tipo de interés fijado por el Banco Central decreció de manera constante. Las autoridades pudieron entonces incrementar la relación existente entre el gasto fiscal y el PIB en casi un 14\% durante el período 2000-2002, en comparación con el valor de 1996, al tiempo que practicaban una política monetaria no restrictiva.

Tal como se indica en el cuadro 2, las condiciones externas que afrontó la economía chilena en el período 2000-2003 fueron similares en magnitud a las condiciones externas prevalecientes en 1982 y 1983. Sin embargo, en 1982 y 1983 tanto el PIB como el gasto público disminuyeron sustancialmente, lo que afectó gravemente a la inversión pública y al gasto social. Por el contrario, en el período 2000-2003 el PIB y el gasto público crecieron al 3,0\% y al 4,2\% respectivamente, lo que contribuyó a reducir la pobreza y mantener el desempleo a niveles relativamente bajos si se compara con la crisis de la década de 1980. 
Cuadro 2

Choques externos y sus impactos, 1982-1983 frente a 2000-2003

(En porcentajes)

\begin{tabular}{lcc}
\hline & $1982-1983$ & $2000-2003$ \\
\hline Índice de condiciones externas (porcentajes del PIB) & $-4,1$ & $-4,4$ \\
\hline PIB (cambios porcentuales) & $-8,5$ & 3,0 \\
\hline Desempleo (promedios anuales porcentuales) & 19,1 & 8,9 \\
\hline Gasto público (cambios porcentuales reales) & $-2,1$ & 4,2 \\
\hline Pobreza (cambios en los índices porcentuales) & 15,0 & $-1,8$ \\
\hline
\end{tabular}

Fuente: Ministerio de Finanzas, "Exposición sobre el estado de la hacienda pública 2004”, Santiago, 2004.

El resultado fue que la nueva combinación de políticas macroeconómicas, y especialmente la regla de política fiscal, ha atenuado el impacto de los choques externos sobre la economía y ha estabilizado el financiamiento de las políticas sociales. Así sucedió también durante la Gran Recesión de 2009. Por ende, se ha convertido en un elemento fundamental de las políticas chilenas de protección social.

La política fiscal anticíclica del período 2000-2002 incluyó un incremento del 9\% en la relación entre el gasto en protección social y el PIB con relación a 1996. Este crecimiento obedeció principalmente a los gastos en desempleo, que habían aumentado constantemente desde el importante incremento que registró el desempleo a finales de 1998, el cual creció dos veces y media más rápidamente que el PIB desde 1996 a 2001-2002 (véase el gráfico 2).

El gasto en desempleo se incrementó durante el período 1999-2002 debido principalmente a un aumento importante en los programas de empleo de emergencia, a saber, los Programas de Empleo con Apoyo Fiscal. Con la experiencia de los años setenta y ochenta como precedente (véase la sección IV), en 1992 volvieron a ponerse en práctica programas de empleo público a escala limitada, cuando el nuevo Gobierno democrático puso en marcha un programa de creación de empleo dirigido por las municipalidades. No obstante, fueron escasos los recursos asignados y la cobertura. En respuesta al incremento en el desempleo que se produjo durante la segunda mitad de 1998, hubo un nuevo ímpetu en 1999 por mejorar los programas de empleo público. Esto incluyó, entre otras medidas, reasignaciones presupuestarias para aumentar el financiamiento de tales programas.

Antes de 1999, era inadecuada la capacidad administrativa existente para los programas de empleo. A raíz de ello, la administración pública se vio presionada a responder rápidamente a las demandas urgentes derivadas de la crisis, y el resultado fue una rápida expansión de los programas de empleo directo que ya estaban en funcionamiento ${ }^{11}$. Los pagos efectuados en virtud de estos programas tenían un monto similar al del salario mínimo. En términos generales, la cobertura total aumentó de casi 10.000 empleos en abril de 1999 a un punto máximo de 100.000 en noviembre de 1999 (véase el gráfico 3). El nuevo Gobierno redujo los programas municipales considerablemente en 2000, por lo que en diciembre la cobertura de ese año no superó los 15.000 empleos.

En resumen, el Gobierno puso en marcha la primera etapa de los programas de empleo (1999-2000) a través de las municipalidades. La idea básica era generar empleo temporal para los trabajadores que habían perdido su empleo. Sin embargo, los programas también atrajeron a un gran número de personas que se habían quedado fuera del mercado laboral. Debido a la persistencia de la crisis y los salarios relativamente atractivos que se pagaban se hizo difícil suprimir los puestos que habían sido concebidos en el marco de programas de empleo temporal.

\footnotetext{
${ }^{11}$ Entre estos programas cabe mencionar el Programa de Generación de Empleo (PGE) y el Programa Mejoramiento Urbano y Equipamiento Comunal (PMU).
} 


\section{Gráfico 3}

Programas de Empleo con Apoyo Fiscal, 1999-2002

(Promedio de empleos financiados por mes)

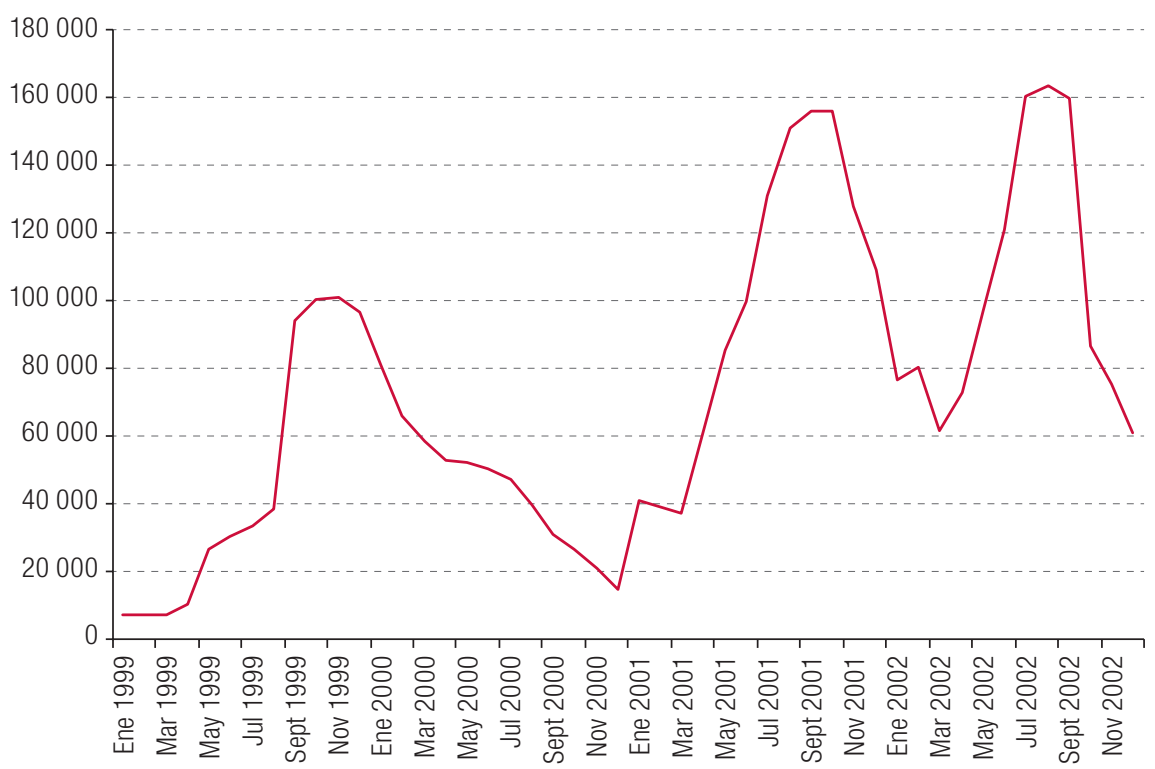

Fuente: Dirección de Presupuestos (DIPRES).

La segunda etapa de los programas de empleo comenzó en 2001, cuando los planes municipales fueron reformulados y se crearon programas nuevos para dotar de flexibilidad a la contratación y a la ejecución de los proyectos. En esta etapa fueron preponderantes los programas de empleo indirecto, como la formación vocacional y los subsidios de duración limitada para la creación de empleo en el sector privado ${ }^{12}$. La aceleración de la inversión en proyectos de infraestructura pública intensivos en mano de obra también se utilizó como instrumento para aumentar la demanda de mano de obra durante la crisis (Guzmán, 2016). De esa forma se dio apoyo indirecto al empleo al incrementar la demanda de mano de obra no cualificada (predominantemente) como consecuencia del aumento de la inversión. En líneas generales, el número promedio de empleos financiados por todos estos programas pasó de 46.000 en 1999 a 100.000 en 2002, y alcanzó su máximo en agosto de 2002 al llegar a los 163.000 (véase el gráfico 3), es decir, casi el 3\% de la fuerza laboral en ese momento (Arenas y Guzmán, 2003).

Las deficiencias de los programas de empleo incluyeron: i) la ausencia de un mecanismo de autoselección para incluir a los trabajadores informales; ii) la duplicación de funciones y costos administrativos entre los programas debida a la superposición de los objetivos y los posibles beneficiarios; y iii) el impacto posiblemente bajo de los programas en cuanto al número de nuevo puesto de trabajo generados como resultado de tales programas, a diferencia del número de empleos financiados (véase Bravo, Contreras y Medrano, 2004; Guzmán, 2016).

\footnotetext{
${ }^{12}$ Entre los ejemplos cabe mencionar el programa de trabajo y de reinserción laboral del Fondo de Solidaridad e Inversión Social (FOSIS) y los subsidios al empleo en el sector privado proporcionados por el Servicio Nacional de Capacitación y Empleo (SENCE).
} 


\title{
IV. Factores institucionales que afectaron a la capacidad del Estado para ampliar los programas de protección social
}

\section{Factores positivos}

\author{
a) La reducción de la deuda pública de los años \\ noventa como mecanismo de autoprotección
}

Entre 1989 y 1999, la deuda bruta del Gobierno central bajó del 47\% al 14\% del PIB. Este declive continuo de la carga de la deuda pública contribuyó de varias formas al mantenimiento de un crecimiento estable del gasto social después de 1999 y de ahí se pasó al ámbito necesario para aumentar los programas de protección social durante la crisis. En primer lugar, la reducción de la deuda dio lugar a un descenso en los recursos que se necesitaban para hacerle frente, con el resultado directo de que quedaron disponibles más recursos para redirigirlos a áreas sociales. A esto se le dio el nombre de "dividendo social" de la política social (Ministerio de Finanzas, 2004).

En segundo lugar, mantener baja la deuda pública constituye un mecanismo de autoprotección para el país, ya que es más probable que exista menos necesidad de aplicar duros ajustes fiscales en caso de que los tipos de interés se eleven rápidamente y las entradas de capital se comporten de forma procíclica como respuesta a los choques comerciales. La continua reducción de la deuda pública durante la reactivación económica contribuyó a crear confianza en la sostenibilidad a largo plazo de la política fiscal aplicada en la crisis. Además, la disminución de la deuda pública en los períodos de reactivación contribuye a asegurar mejores condiciones externas para la obtención de préstamos durante las recesiones (Arenas de Mesa y Guzmán, 2003). En efecto, el Gobierno llevó a cabo varias operaciones de bonos soberanos en el período 1999-2002 y obtuvo más de 2.000 millones a diferenciales inferiores a los del conjunto de la región de América Latina y el Caribe ${ }^{13}$. En ese período, Chile presentó la calificación de riesgo del país más baja de la región y sus políticas macroeconómicas fueron evaluadas positivamente en las puntuaciones internacionales de competitividad (véase Foro Económico Mundial, 2004).

\section{b) El Fondo de Estabilización de los Ingresos del Cobre como mecanismo de autoseguro}

El Fondo de Estabilización de los Ingresos del Cobre (FEC) fue creado en 1985 con el fin de moderar las fluctuaciones en los ingresos fiscales resultantes de los cambios en el precio del cobre. Su propósito principal es ahorrar recursos cuando el precio vigente se sitúe por encima del precio estimado a largo plazo (conocido como precio de referencia) para que estos recursos puedan usarse cuando el precio vigente es inferior. Por otra parte, el Gobierno ha utilizado algunas veces los recursos acumulados para amortizar la deuda pública. El fondo es administrado por el Banco Central, lo que sirve de garantía contra un uso discrecional ya que esa institución es independiente del Gobierno central ${ }^{14}$.

El FEC puede categorizarse como un mecanismo de autoseguro a nivel de país que permite transferir recursos desde los ciclos económicos expansivos a los ciclos adversos a fin de mitigar los

\footnotetext{
${ }^{13}$ Para un debate sobre este punto, véase Ministerio de Finanzas (2002).

${ }^{14}$ Para una descripción detallada de las operaciones y las normas del FEC, véase Arellano (2005).
} 
efectos adversos de los choques comerciales. Tal como muestra el gráfico 4, cuando los efectos estabilizadores del plan del FEC se suprimen los ingresos del cobre fluctúan en gran medida cada año. Estos varían mucho menos cuando se incluyen los flujos netos del FEC.

\section{Gráfico 4}

Ingresos fiscales del cobre antes (brutos) y después (netos) de la operación del Fondo de Estabilización de los Ingresos del Cobre (FEC), 1987-2004

(En porcentajes del PIB)

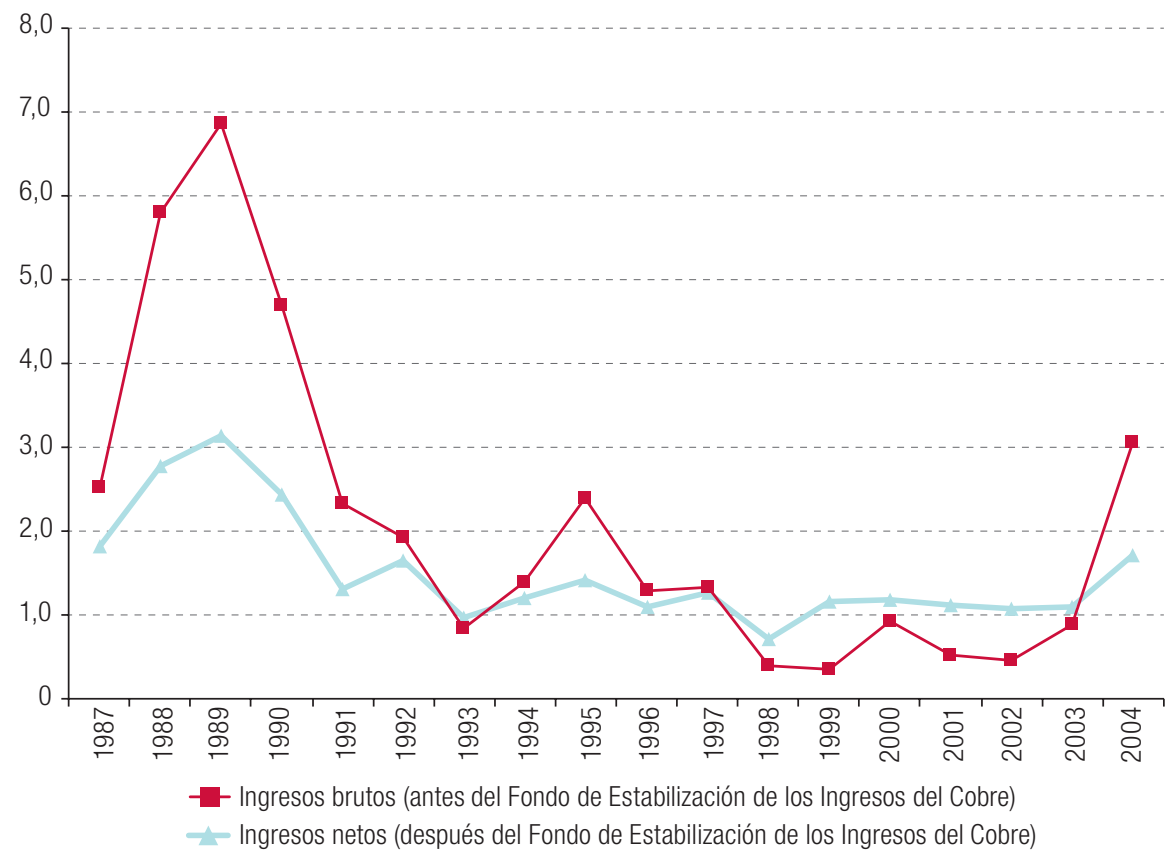

Fuente: J. P. Arellano, "Del déficit al superávit fiscal: razones para una transformación estructural en Chile", Serie Estudios Socio/ Económicos, No. 25, Santiago, Corporación de Investigaciones Económicas para América Latina, 2005; y el Tesoro General de la República de Chile.

Antes de la creación del FEC, era probable que el gasto público aumentara tras un alza (transitoria) de los ingresos, por lo que se hacía difícil reducir el gasto público en caso de producirse un marcado empeoramiento de los términos de intercambio. Como en otras economías de América Latina y el Caribe, hasta ese momento los gobiernos chilenos no habían logrado habitualmente prepararse para los momentos difíciles ahorrando en los momentos de bonanza, y carecían de una base de ingresos fiscales suficientemente diversificada. La creación del FEC, junto con la regla fiscal que se explica más adelante, ayudó a colocar el crecimiento del gasto fiscal en una senda más sostenible, gracias a lo cual la política fiscal pudo desempeñar un papel anticíclico incluso durante la desaceleración económica de 1999. Los recursos obtenidos del FEC alcanzaron un promedio de 291 millones de dólares al año durante el período 1999-2003 y contribuyeron a mantener constante el crecimiento del gasto social en ese período, ya sea directamente (a causa de los ingresos adicionales) o indirectamente (porque debido a los prepagos se necesitaban menos recursos para amortizar la deuda).

\section{c) La regla del superávit estructural como mecanismo de autoseguro}

Desde el presupuesto de 2001, el Gobierno ha incorporado al mecanismo de estabilización no solo las fluctuaciones en el precio del cobre sino también las variaciones en los ingresos fiscales 
causadas por las fluctuaciones en el crecimiento del PIB con respecto a su tendencia a largo plazo. Esta incorporación se introdujo como una estimación de los ingresos estructurales de la tendencia a largo plazo, de modo que los gastos corrientes pudieran calcularse a partir de una base a medio plazo. Por ende, el balance estructural refleja la cantidad de ingresos y gastos si la economía estuviera operando a su máximo potencial y el cobre se comercializara a su precio a medio plazo ${ }^{15}$.

Este mecanismo incluye una norma fiscal autoimpuesta que requiere un superávit estructural cuyo nivel se estableció inicialmente en el 1\% del PIB. Esta norma permite que los estabilizadores presupuestarios automáticos funcionen plenamente sin tener que ajustar la política fiscal en ninguna fase del ciclo. Quiere decir que puede seguirse una política fiscal anticíclica, dado que la senda del gasto se deriva de los ingresos estructurales. A consecuencia de ello, han sido sustancialmente menores las variaciones en el gasto. En el gráfico 5 se presentan los resultados de su aplicación durante 1997-2005.

\section{Gráfico 5}

Balances fiscales efectivos y estructurales, 1997-2005

(En porcentajes del PIB)

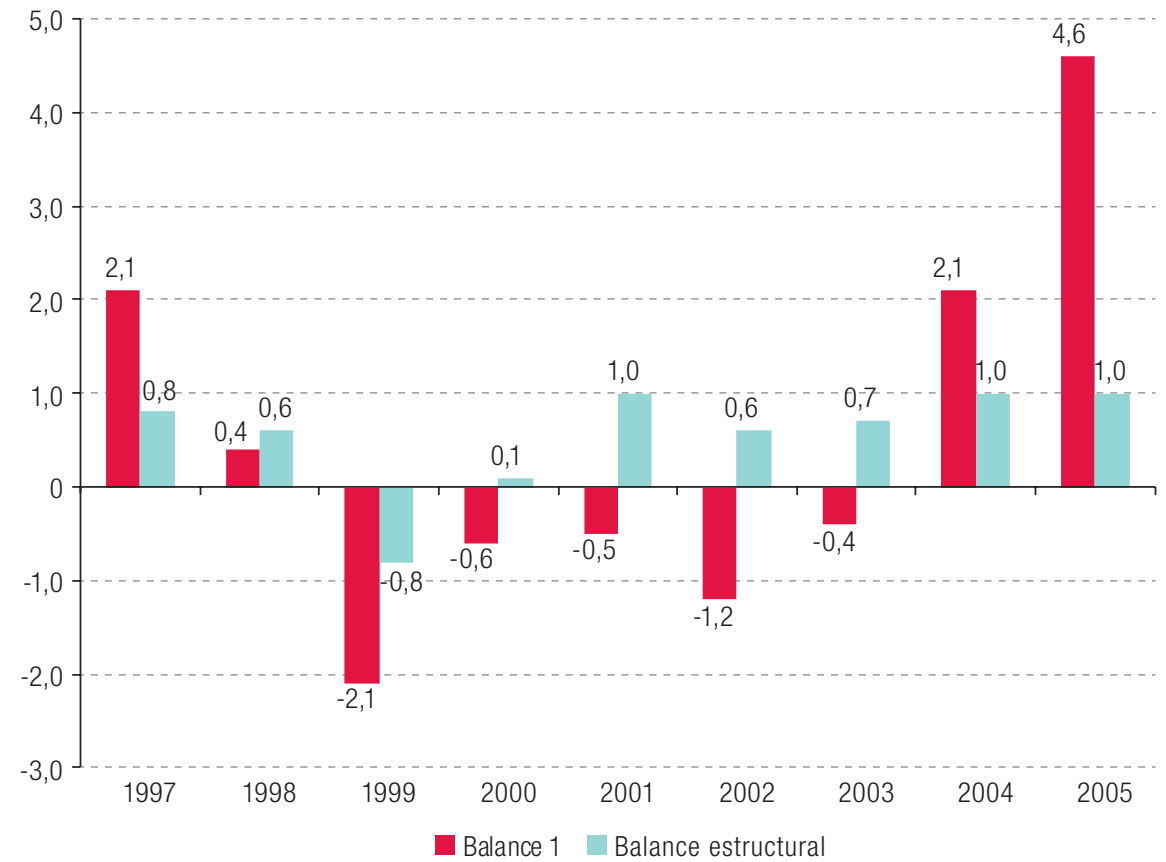

Fuente: Dirección de Presupuestos (2010).

Según la clasificación de Gill y llahi (2000), la regla fiscal de Chile puede considerarse una medida de autoseguro a nivel del país. Al igual que un fondo de estabilización, transfiere recursos desde los ciclos económicos expansivos a los ciclos adversos. Además, al buscar la sostenibilidad a largo plazo de la política fiscal y dar una señal clara de disciplina fiscal a los mercados, la regla operaría como mecanismo de autoprotección, reduciendo la posibilidad del contagio financiero de las crisis que afectan a otros países de la región. A pesar de que en el período 2001-2003 Chile presentó déficits fiscales, tuvo uno de los diferenciales de deuda soberana más bajos de la región y vio cómo caía la correlación con los diferenciales de otros mercados emergentes. Esto demuestra que una regla fiscal eficaz y creíble puede servir de protección contra el riesgo macroeconómico (Banco Mundial, 2005).

\footnotetext{
${ }^{15}$ En la norma fiscal se incluye el sistema del FEC tal como se explica en la letra b). Véase Marcel y otros (2001) y el Ministerio de Finanzas (2001) si se quiere obtener una descripción detallada de la metodología del balance estructural y sus normas de operación, y Larraín y otros (2011) para un análisis de los cambios más recientes.
} 


\section{d) Nueva mezcla de políticas fiscal, cambiaria y monetaria}

Además de implementar la nueva regla fiscal, Chile adoptó una nueva combinación de políticas fiscal, cambiaria y monetaria. Desde 1999, el objetivo principal de las políticas del Banco Central ha sido mantener la inflación anual en el rango del 2\% al 4\%. También en 1999, la política cambiaria pasó de un plan de bandas a un régimen de libre flotación. Estas medidas tuvieron por objeto obtener una mejor protección contra los choques externos, así como una mayor independencia de la política monetaria en un momento de creciente integración en los mercados financieros internacionales.

La aplicación de la regla fiscal tuvo mayores implicaciones para la relación existente entre la política fiscal y monetaria (Dirección de Presupuestos, 2000). Como se ha mencionado, la regla fiscal permite el pleno funcionamiento de los estabilizadores presupuestarios automáticos sin tener que ajustar la política fiscal a las fases del ciclo. Por consiguiente, la política monetaria tiene un papel preponderante de estabilización a corto plazo que, en combinación con una política cambiaria completamente flexible, puede realizar la función de controlar la inflación y reducir la variabilidad del producto. Así pues, el plan requiere una amplia coordinación entre las políticas fiscal y monetaria, dado que el margen del papel de estabilización de la política monetaria depende de lo bien que se cumpla la regla fiscal.

Este nuevo marco normativo ha sido muy eficaz desde 2000. En particular, en 2001 y 2002 los tipos de interés se mantuvieron sustancialmente bajos durante la nueva fase negativa del ciclo. Gracias a ello la política monetaria desempeñó un papel de estabilización a través de una mejora en la coordinación de la política macroeconómica. Así, la política fiscal ejerció un papel anticíclico desde 2000 pero, a diferencia de 1998 y 1999, esto no colocó una mayor presión sobre el tipo de interés. Por tanto, no hay duda de que la economía chilena quedó mejor situada para absorber los efectos de los choques futuros.

Del mismo modo, el Banco Central ha mostrado su compromiso con la flexibilidad cambiaria desde que se puso en marcha el régimen de flotación cambiaria en 1999, lo que permitió que el tipo de cambio fluctuase en respuesta a los diferentes choques. La credibilidad del régimen de flotación ha disminuido considerablemente los descalces de moneda entre los activos y los pasivos del sector empresarial y ha mejorado la función que cumple la flexibilidad cambiaria consistente en ayudar a la economía a ajustarse a los choques externos (Claro y Soto, 2013).

\section{e) Medidas preparatorias adoptadas por el Banco Central antes de aplicar el régimen de libre flotación cambiaria}

La adopción de un régimen de libre flotación cambiaria en septiembre de 1999 se basó en la evaluación de que el Banco Central tenía un historial suficientemente creíble en controlar la inflación, de que se habían desarrollado más los mercados de cobertura y de que en el sector privado no había ningún descalce de moneda grave (Claro y Soto, 2013). Como se ha dicho antes, estas condiciones positivas fueron principalmente el resultado de las medidas preparatorias adoptadas por el Banco Central antes de la flotación.

Para lograr una transición eficaz a un régimen de tipo de cambio flexible hace falta una gestión correcta de una serie de cuestiones institucionales y operativas. Según Duttagupta, Fernández y Karacadag (2005), hay indicios que demuestran que generalmente se necesitan cuatro cosas: i) un mercado cambiario profundo y líquido; ii) intervenciones coherentes del Banco Central en el mercado cambiario; iii) un estabilizador nominal alternativo que sea adecuado para sustituir al tipo de cambio fijo; y iv) gestión y supervisión efectivas de la exposición de los sectores público y privado al riesgo cambiario. 
A la luz de estos requisitos, Ötker-Robe y otros (2007) analizan los aspectos operativos de la transición chilena de un régimen fijo a otro de flotación llevada a cabo en 1999. Lo primero que argumentan es que el mercado cambiario, incluidos los mercados al contado y a plazos, se desarrollaron de forma constante durante la década de 1990, ya que con el tiempo las autoridades liberalizaron las regulaciones que afectaban a las operaciones de arbitraje, autorizaron las transacciones de canje, facilitaron el acceso a dichos mercados y permitieron una mayor flexibilidad cambiaria dentro de la banda deslizante. Asimismo, en preparación para la flotación, en 1998 y 1999 el Banco Central introdujo nuevos instrumentos de cobertura cambiaria en forma de pagarés indexados al dólar (PRD) ${ }^{16}$, puso en práctica nuevas regulaciones sobre derivados que cubrían la negociación de contratos de futuros en pesos y en otras monedas, entre otras cosas, y cambió una serie de requisitos para mejorar el ajuste monetario de las transacciones comerciales bancarias (Banco Central de Chile, 1998 y 1999). Así, en 1999 los mercados nacionales (onshore) al contado, a plazos y de canje y el mercado exterior (offshore) de contratos a plazo no entregable (NDF) estaban suficientemente desarrollados (Ahumada y Selaive, 2007).

Sobre el segundo requisito, las intervenciones coherentes del mercado cambiario, un gobierno que quiera desplazarse hacia un régimen flexible debe formular políticas sobre los objetivos, el plazo y las cantidades de la intervención (Duttagupta, Fernández y Karacadag, 2005). En el momento que se cambió el régimen, las autoridades anunciaron una nueva estrategia de intervención: el Banco Central suspendió indefinidamente su compromiso formal con la banda cambiaria, pero retuvo el derecho a intervenir en circunstancias excepcionales, como un incremento súbito de la volatilidad cambiaria no justificada por las principales variables (véase el Banco Central de Chile, 1999). A raíz de ello, el Banco Central ha intervenido varias veces desde 1999, especialmente en 2001 y 2002. Las intervenciones han sido transparentes y han sido anunciadas con tiempo, incluidos los detalles del período concreto durante el cual el Banco Central podría intervenir y las cantidades máximas por comprometer (Ötker-Robe y otros, 2007). El anuncio previo y la estipulación de un período específico demostraron que se mantenía el compromiso con un régimen completamente flotante (Morandé y Tapia, 2002).

El tercer requisito fue el reemplazo del tipo de interés fijo por un estabilizador nominal alternativo adecuado. Durante la década de 1990 se aplicó una política monetaria que fijaba metas de inflación decreciente anunciadas explícitamente cada año y usaba la banda cambiaria deslizante como estabilizador nominal. Cuando se abolió la banda, el Banco Central anunció una nueva meta de inflación a partir de finales de 2000: la inflación anual debía mantenerse en el rango del 2\% al 4\% (centrada en el 3\%) en un horizonte superior a un año (24 meses). Se estableció entonces una meta de inflación propiamente dicha y se abolió la banda deslizante, con lo que el objetivo de inflación se convirtió en el único estabilizador para las expectativas de inflación en un sistema plenamente flotante (Ötker-Robe y otros, 2007). Además, en agosto de 2001 el Banco Central pasó de fijar su propio tipo de interés real a otro nominal. Se trataba de una medida lógica tras la liberalización cambiaria y la apertura de las cuentas de capital, dada la necesidad de aumentar la transparencia en la aplicación de la política monetaria (Banco Central de Chile, 2001). Con anterioridad, el tipo de interés fijado por el Banco Central se había indexado a la inflación anterior, algo útil cuando la inflación era alta y volátil, como en la década de 1980. No obstante, un tipo de interés real es difícil de manejar en períodos de inflación baja y crecimiento reducido o negativo. En situaciones de ese tipo, la política más apropiada puede consistir en fijar un tipo de interés real negativo, pero, aunque los tipos de interés reales negativos explícitos pueden usarse para los depósitos bancarios, no pueden utilizarse como instrumento macroeconómico ${ }^{17}$. Por consiguiente, este cambio amplió la gama de las opciones de política monetaria en una época en que tales opciones se reducían gradualmente como resultado de una inflación decreciente (Fuentes y otros, 2003).

\footnotetext{
${ }^{16}$ Estos pagarés fueron sustituidos por bonos del Banco Central denominados en dólares (BCD) en 2002.

17 Agradezco a un árbitro anónimo por plantear este tema.
} 
El cuarto elemento de las medidas previas a la flotación fue la gestión y la supervisión eficaces del riesgo cambiario. Durante la década de 1990, la banda cambiaria ofrecía a los agentes privados un seguro implícito contra el riesgo cambiario, lo que a su vez generaba riesgo moral. En consecuencia, los agentes privados mostraban una tendencia a asumir posiciones un tanto riesgosas en forma de importantes pasivos netos en divisas. Antes de la flotación, el Banco Central reforzó las regulaciones sobre dichos pasivos netos y respecto a los vencimientos y desequilibrios de las tasas de interés. Por lo que respecta al sector bancario, en agosto de 1998 el Banco Central retuvo el antiguo límite de exposición a la moneda del $20 \%$ del capital básico pero la computación de los descalces distinguía entre las monedas (Cowan y De Gregorio, 2007). En 1999, se revisaron las regulaciones de los descalces de moneda a fin de incorporar todas las operaciones cambiarias y se introdujeron nuevas reglas para administrar la liquidez y el riesgo de tipo de interés. Se permitieron las transacciones de derivados y en 1999 se abolió el requisito de autorización para participar en estas transacciones con contrapartes externas (Ötker-Robe y otros, 2007). El sector empresarial tuvo una actitud prudente respecto del riesgo de descalces de moneda, incluso en el período previo a la flotación (Cowan y De Gregorio, 2007), y probablemente la banda deslizante que se ampliaba gradualmente brindaba una garantía limitada implícita a aquellos que mantenían pasivos extranjeros no cubiertos, lo que limitaba las exposiciones sin cobertura (De Gregorio y Tokman, 2005). Además, el mercado a plazos ya estaba bastante desarrollado, lo que facilitaba la gestión de los riesgos cambiarios.

\section{Factores negativos}

\section{a) Ausencia de interacción sistemática entre los programas y duplicación de funciones y objetivos}

El progreso estable y el financiamiento del sistema de protección social ayudaron a atenuar el impacto de la desaceleración económica de 1999 en los hogares pobres. Sin embargo, es probable que durante el choque de 1999 la falta de un sistema de protección social más desarrollado acabara afectando al alcance del fortalecimiento de los programas de protección social.

En particular, la ausencia de un marco institucional común y la interacción sistemática entre las instituciones públicas disminuyeron la eficacia de los programas de empleo en cuanto a la cobertura y la duplicación de funciones. Los programas de empleo presentaron bastantes superposiciones en sus objetivos y posibles beneficiarios, lo que causó duplicación de funciones y costos administrativos.

\section{b) Capacidad administrativa instalada insuficiente antes de la crisis}

La insuficiencia de la capacidad administrativa instalada antes de la crisis complicó considerablemente la tarea de crear un aparato público capaz de responder con rapidez a las demandas urgentes generadas por la crisis. Sin embargo, poco tiempo después se había ampliado una nueva serie de programas públicos en respuesta a la crisis. La cobertura alcanzada por los programas en un corto espacio de tiempo fue de hecho muy notable, aunque esta falta de capacidad administrativa tocó de lleno a algunas instituciones públicas, como el Servicio Nacional de Capacitación y Empleo (SENCE), (Bravo, Contreras y Medrano, 2004), que tuvieron no solo que ocuparse de sus programas regulares sino además llevar a cabo nuevas tareas de reubicación de recursos humanos y cumplir los exigentes objetivos de cobertura respecto al número de beneficiarios cubiertos cada mes por los programas respectivos. 


\section{c) Inercia en los gastos incurridos antes de la crisis}

La capacidad de las instituciones de ampliar los programas de protección social tras el advenimiento de la crisis se vio afectada por la rigidez y la inercia de una proporción elevada de los gastos fiscales. Antes del estallido de la crisis, una gran parte del gasto ya estaba comprometido como resultado de las leyes permanentes relativas a las amplias reformas iniciadas antes de ese momento. Así sucedió, por ejemplo, con las reformas educativa y judicial empezadas en la década de 1990. Antes de 2000, ya se había comprometido cerca del $76 \%$ de los gastos públicos incluidos en el presupuesto de 2000. Este porcentaje se desglosa de la manera siguiente: 1) el 66\% del total de gastos ya comprometidos debido a las leyes permanentes sobre pensiones, subsidios y pagos a empleados del sector público; y 2) el 10\% del total de gastos ya aprobados para pagar gastos de inversión retrasados a proyectos puestos en marcha en años anteriores. Solo el $24 \%$ del total de gastos en el presupuesto de 2000 aún no había sido comprometido (gasto discrecional).

En consecuencia, el aumento de los recursos necesarios para ampliar los programas se logró en parte reduciendo los gastos discrecionales (es decir, los gastos no aprobados previamente). A consecuencia de ellos se retrasaron algunas nuevas iniciativas no relacionadas con los programas de empleo y se redujo el alcance de los aumentos de gastos en programas de contingencia.

Podría así sostenerse que hubo que buscar un equilibrio entre una mayor ampliación de los programas de empleo y el cumplimiento de los compromisos relacionados con las reformas ya iniciadas antes de la crisis (como las reformas educativa y judicial) y las reformas nuevas puestas en marcha después de 2000 (como la reforma del sistema de salud).

\section{Observaciones finales}

Las políticas chilenas de protección social han pasado por un proceso de aprendizaje debido a varios choques macroeconómicos. Concretamente, la crisis de la deuda de 1982-1983, la depresión asiática de 1997-1998 y la Gran Recesión de 2008 han influido en las políticas macroeconómicas y en las reformas económicas implementadas en Chile durante las últimas décadas.

En este contexto, el presente artículo tiene por objeto brindar una introducción a la experiencia chilena de hacer frente a la recesión de 1999 analizando la manera en que algunas de las políticas adoptadas en su momento permitieron que un fuerte crecimiento del gasto social fuera acompañado de una política fiscal equilibrada. La experiencia chilena podría servir como un punto de partida para explorar soluciones innovadoras de protección social aplicadas en otros países latinoamericanos, con vistas a que las inversiones sociales a largo plazo y la consolidación fiscal a medio plazo se apoyen mutuamente y sean sostenibles.

En este artículo se afirma que, a posteriori, la política de ajuste aprobada en 1997-1998 puede considerarse inadecuada. La falta de coordinación entre las políticas monetaria y fiscal adoptadas en ese período agravaron los efectos de los choques externos iniciales que afrontaba Chile (a saber, la reducción de los flujos de capital, el empeoramiento de los términos de intercambio y el contagio de las crisis de otros países). El episodio de iliquidez de 1998 hizo que la economía se contrajera más de lo necesario y esto afectó gravemente a la inversión y a las decisiones de consumo del sector privado al tiempo que prolongó los efectos sobre el desempleo.

Aunque las políticas macroeconómicas adoptadas durante la recesión fueron inapropiadas, la disciplina fiscal y las sólidas instituciones públicas establecidas antes y después de la crisis mejoraron las políticas de protección social de Chile. En concreto, la disminución de la deuda pública en la década de 1990, el Fondo de Estabilización de los Ingresos del Cobre creado en 1985, la adopción 
de la regla del superávit estructural del 1\% del PIB en 2000 y la nueva combinación de políticas fiscal, cambiaria y monetaria aprobada desde la recesión, han reducido o mitigado el riesgo de otras conmociones y, por ende, de la vulnerabilidad de la economía chilena a esos trastornos. El resultado fue que Chile pudo poner en práctica una política fiscal anticíclica durante el período 2000-2003 y la Gran Recesión.

En el presente estudio se señalan tres temas fundamentales que afectaron al alcance de la ampliación de los programas de protección social en la recesión de 1999. En primer lugar, el alcance se vio limitado por la ausencia de interacción sistemática entre los programas y la duplicación de funciones y objetivos. En segundo lugar, la capacidad administrativa instalada inadecuada antes de la crisis restringió las opciones del Gobierno y su capacidad de ampliar los múltiples programas de empleo con objetivos comunes y superposiciones en sus posibles beneficiarios. Por último, la inercia de los gastos incurridos antes de la recesión fue un factor que limitó el potencial de aumentar los recursos asignados a los programas de contingencia.

Las estrategias chilenas de desarrollo adoptadas durante las últimas décadas han sido eficaces en términos de crecimiento económico y alivio de la pobreza. No obstante, se deben adoptar importantes medidas para validar dichas estrategias como modelo de desarrollo efectivo para alcanzar una protección social real y promover el crecimiento inclusivo y más igualitario a largo plazo. Para poder convertirse en un modelo válido para otros países latinoamericanos, el sistema chileno de desarrollo debe alcanzar resultados satisfactorios de forma sistemática tanto en lo que respecta al crecimiento económico como en la forma de que éste se distribuye entre los ciudadanos (Ffrench-Davis, 2014).

Por lo tanto, es esencial que Chile lleve a cabo reformas estructurales de alta calidad que combinen el crecimiento económico, la estabilidad política y las estrategias innovadoras. Estas reformas deben basarse en logros anteriores y en la experiencia acumulada en anteriores choques macroeconómicos. En el presente artículo se ha pretendido llamar la atención a esa experiencia acumulada para que sea tomada en cuenta en el diseño de las reformas políticas y que se puedan compartir las lecciones de todos los países.

\section{Bibliografía}

Ahumada, L. A. y J. Selaive (2007), "Desarrollo del mercado de derivados cambiarios en Chile", Revista de Análisis Económico, vol. 22, No. 1.

Arellano, J. P. (2005), "Del déficit al superávit fiscal: razones para una transformación estructural en Chile", Serie Estudios Socio/Económicos, No. 25, Santiago, Corporación de Investigaciones Científicas para Latinoamérica.

Arenas de Mesa, A. y J. Guzmán (2003), "Fiscal policy and protection in Chile", CEPAL Review, No. 81, Santiago, Comisión Económica para América Latina y el Caribe (CEPAL).

Atria, F. (2014), Derechos sociales y educación: un nuevo paradigma de lo público, Santiago, LOM Ediciones. Atria, F. y otros (2013), El otro modelo: del orden neoliberal al régimen de lo público, Santiago, Debate.

Banco Central de Chile (2001), Informe de política monetaria, Santiago. (1999), Memoria anual 1999, Santiago.

- (1998), Memoria anual 1998, Santiago.

Banco Mundial (2005), Household Risk Management and Social Protection in Chile, Washington, D.C.

Bravo, D., C. Contreras y P. Medrano (2004), "Informe final. Evaluación de impacto: programas de empleo con apoyo fiscal", Santiago, Universidad de Chile [en línea] www.dipres.cl.

Calvo, G. y C. Reinhart (2002), "Fear of floating", The Quarterly Journal of Economics, vol. 117, No. 2, Oxford, Oxford University Press.

Claro, S. y C. Soto (2013), "Exchange rate policy and exchange rate interventions: the Chilean experience", BIS Papers, No. 73, Bank for International Settlements [en línea] https://www.bis.org/publ/bppdf/bispap73.pdf. 
Contreras, D. (2009), "Poverty, inequality and welfare in a rapid growth economy: the Chilean experience", The Poorest and the Hungry: Assessments, Analyses, and Action, J. von Braun, R. Vargas Hill y R. PandyaLorch (eds.), Washington, D.C., International Food Policy Research Institute (IFPRI).

Corbo, V. y J. Tessada (2003), "Growth and adjustment in Chile: a look at the 1990s", Working Paper, No. 204, Santiago, Banco Central de Chile.

Cowan, K. y J. de Gregorio (2007), "International borrowing, capital controls, and the exchange rate: lessons from Chile", Capital Controls and Capital Flows in Emerging Economies: Policies, Practices and Consequences, Cambridge, Massachusetts, National Bureau of Economic Research.

De Ferranti, D. y otros (2000), Securing Our Future in a Global Economy, Washington, D.C., Banco Mundial.

De Gregorio, J. (2005), "Crecimiento económico en Chile: evidencia, fuentes y perspectivas", Estudios Públicos, No. 98, Santiago, Centro de Estudios Políticos.

De Gregorio, J. y A. Tokman (2005), "El miedo a flotar y la política cambiaria en Chile", Economía Chilena, vol. 8, No. 3, Santiago, Banco Central de Chile.

Duttagupta, R., G. Fernández y C. Karacadag (2005), "Moving to a flexible exchange rate: how, when, and how fast?", Economic Issues, No. 38, Washington, D.C., Fondo Monetario Internacional (FMI).

Ffrench-Davis, R. (2014), "Is Chile a model for economic development?", Serie de Documentos de Trabajo, No. 392, Santiago, Universidad de Chile.

Ffrench-Davis, R. y J. L. Machinea (2007), Economic Growth with Equity: Challenges for Latin America, Santiago, Comisión Económica para América Latina y el Caribe (CEPAL).

Foro Económico Mundial (2004), "Resumen ejecutivo", Ginebra.

Fuentes, R. y otros (2003), "Efectos de la nominalización de la política monetaria en Chile", Working Paper, No. 197, Santiago, Banco Central de Chile.

Gill, I. y N. Ilahi (2000), "Economic insecurity, individual behavior, and social policy", Working Document, No. 31522, Washington, D.C., Banco Mundial.

Guzmán, J. (2016), "Social protection during recessions: evidence from Chile", Journal of Economic Policy Reform, vol. 19, No. 4, Taylor \& Francis.

Larraín, F. y otros (2011), "Una política fiscal de balance estructural de segunda generación para Chile", Estudios de Finanzas Públicas, Santiago, Ministerio de Finanzas.

Marcel, M. y otros (2001), "Balance estructural del gobierno central: metodología y estimaciones para Chile: 1987-2000”, Estudio de Finanzas Públicas, Santiago.

Mayol, A. (2012), El derrumbe del modelo: la crisis de la economía de mercado en el Chile contemporáneo, Santiago, LOM Ediciones.

Ministerio de Finanzas (2004), "Exposición sobre el estado de la hacienda pública 2004”, Santiago. (2002), "Exposición sobre el estado de la hacienda pública 2002”, Santiago.

_-(2001), "Exposición sobre el estado de la hacienda pública 2001", Santiago.

Morandé, F. y M. Tapia (2002), "Exchange rate policy in Chile: from the band to floating and beyond”, Working Paper, No. 152, Santiago, Banco Central de Chile.

OCDE (Organización de Cooperación y Desarrollo Económicos) (2015), OECD Economic Surveys: Chile 2005, París.

Oficina de Asuntos Presupuestarios (2000), "Aspectos macroeconómicos del proyecto de ley de presupuestos del sector público del año 2001" [en línea] http://www.dipres.gob.cl/597/articles-37473_doc_pdf.pdf. (1999), "Aspectos macroeconómicos del proyecto de ley de presupuestos del sector público del año 2000" [en línea] http://www.dipres.gob.cl/598/articles-37476_doc_pdf.pdf.

Ötker-Robe, I. y otros (2007), "Moving to greater exchange rate flexibility: operational aspects based on lessons from detailed country experiences", Occasional Paper, No. 256, Washington, D.C., Fondo Monetario Internacional (FMI). 